\title{
Spigelian hernia
}

\author{
Bhatia TP' ${ }^{1}$, Ghimire $\mathbf{P}^{1}$, Panhani ML ${ }^{1}$
}

${ }^{1}$ Department of General Surgery, Manipal College of Medical Sciences, Pokhara, Nepal

\begin{abstract}
A Spigelian hernia (or lateral ventral hernia) is a hernia through the spigelian fascia, which is the aponeurotic layer between the rectus abdominis muscle medially, and the semilunar line laterally. So far, about 1000 cases have been reported worldwide. These hernias are difficult to diagnose as they do not present with a subcutaneous swelling and have high risk of going for strangulation. We discuss the case of a 36 year old female who presented with history of pain and lumpiness in left lower abdomen, both of which decreased on lying down. She presented to emergency with an episode severe pain at same site which subsided spontaneously. Diagnosis was confirmed on C T scan, plication and onlay prolene mesh repair performed. Spigelian hernias are rare, interparietal type of hernias which have high risk undergoing strangulation. Knowledge of symptoms and signs is vital to diagnosis and treatment of these rare type of hernias.
\end{abstract}

Key words: Spigelian hernia, Interparietal hernia, Rare hernias

\begin{abstract}
Spigelian hernia (or lateral ventral hernia) is a Ahernia through the spigelian fascia, which is the aponeurotic layer between the rectus abdominis muscle medially, and the semilunar line laterally. These hernias almost always develop at or below the linea arcuata, probably because of the lack of posterior rectus sheath. These are generally interparietal hernias, they do not lie below the subcutaneous fat but penetrate between the muscles of the abdominal wall; therefore, there is often no notable swelling.
\end{abstract}

Spigelian hernias are usually small and therefore risk of strangulation is high. Most occur on the right side. Most of these occur between $4^{\text {th }}$ to 7 th decade of life. Compared to other types of hernias, they are rare ${ }^{1}$. The incidence is equal in both males and females.

These hernias are difficult to diagnose. Patients present with intermittent lump and localized pain in uncomplicated cases and are usually misdiagnosed. In developing countries with lack of facilities in towns and villages such cases usually present with intestinal obstruction and even strangulation.

Spigelian hernias should be repaired early as they have high risk of going for strangulation ${ }^{2}$. The repair is simple and can be done by open method or recently introduced laparoscopic repairs which have the advantage of decreased hospitalisation and faster recovery. Large defects require mesh prosthesis.

\section{Case report}

We present the case of a 32 years old female who presented to the emergency for swelling and localized pain in left lower abdomen. The patient gave history of lumpiness and discomfort in same region a couple of times before in the last one year. This acute episode subsided after she was made to lie down. A vague lump was palpable at lateral border of left rectus abdominis during the episode but not felt after the pain subsided. During abdominal ultrasound a small hypoechoic lesion of size $17 \mathrm{~mm}$ X $5.9 \mathrm{~mm}$ was seen in left iliac fossa with $6 \mathrm{~mm}$ defect in muscular plane likely to be omentum or bowel loop.

To confirm the diagnosis a CT Scan was done with increased abdominal pressure by making the patient blow, in supine position. Scan showed weakness and thinning of left anterior abdominal wall over a stretch of $6 \mathrm{cms}$ at lower paramedian region, just lateral to lateral border of left rectus abdominis muscle. There were two distinct small gaps seen, one anterosuperior and another inferomedial to the weakness. Findings were confirmed in prone position.

This confirmed the diagnosis of Spigelian hernia and patient was taken for surgery under general anaesthesia.

\footnotetext{
Correspondence

Dr. Tanuj Paul Bhatia

Lecturer, Department of General Surgery

Manipal College of Medical Sciences

Phulbari, Pokhara

E-mail: dr.tanujpaulbhatia@gmail.com
} 
Just before surgery the position of the opening was identified and marked under ultrasound guidance. This helped in planning of the incision. An oblique incision was made and deepened through subcutaneous fat. After opening the external oblique along the direction of its fibres the hernia came into view (Fig. 1). The sac was opened (Fig. 2), contents checked and redundant part of sac excised (Fig. 3).

The lower opening was just palpable at the inferomedial region of the weakness. Both the openings were plicated

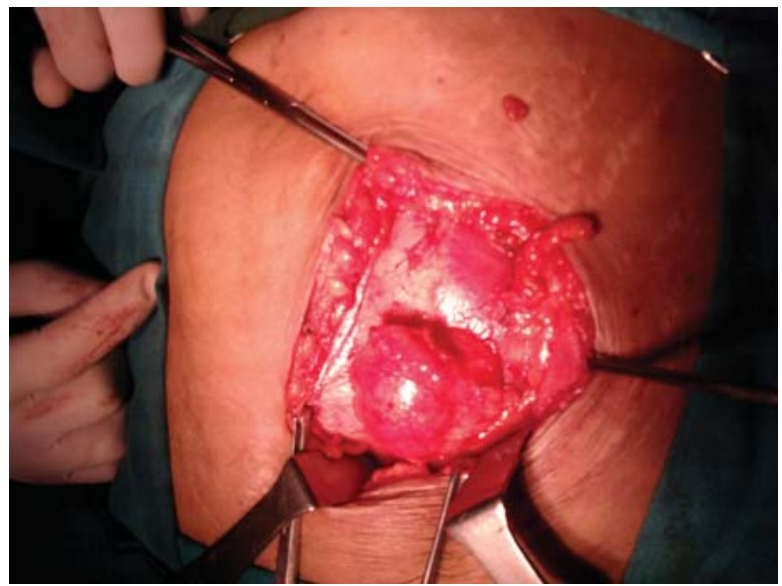

Fig 1: Hernia seen lateral to rectus abdominis with 2-0 prolene suture and the entire area of weakness was re-inforced with an onlay prolene mesh.

Abdomen was closed in layers with external oblique being closed over the mesh after keeping a suction drain in the plane. Patient was allowed orally in the evening and drain was removed after 36 hours. Postoperative recovery of patient was smooth and she was discharged on the third post operative day.

Patient has reported twice for followup and has been doing well.

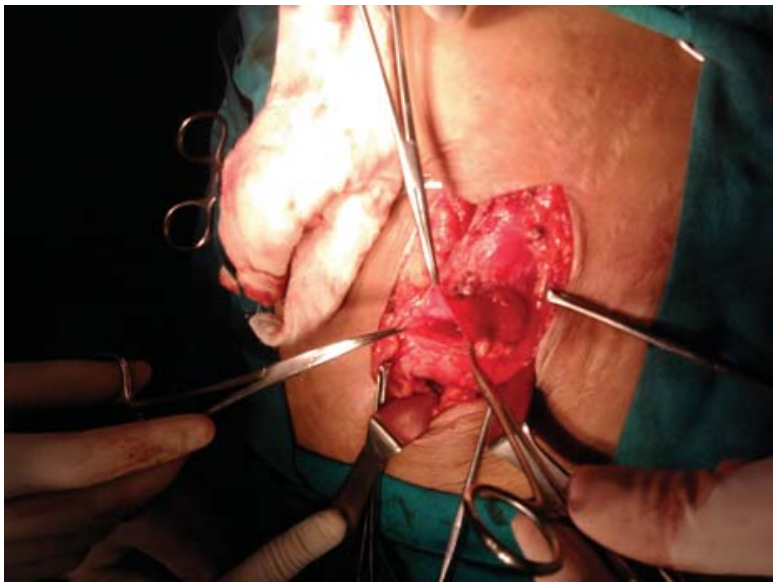

Fig 2: Hernial sac opened

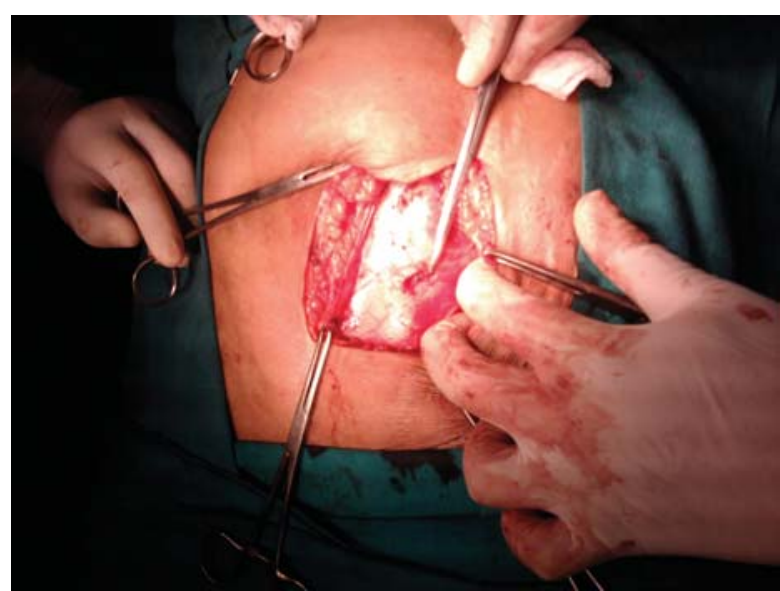

Fig 3: Defect in the spigelian fascia. 


\section{Discussion}

Spigelian hernias are uncommon and frequently pose a diagnostic challenge ${ }^{3}$. It has been estimated that it constitutes $0.12 \%$ of abdominal wall hernias ${ }^{4}$.

Unusual presentations of spigelian hernia have also been reported like spigelian hernia involving the appendix ${ }^{3}$. Also, a case of neonatal bilateral spigelian hernia associated with undescended testis has been reported ${ }^{5}$.

Spigelian hernia is in itself very rare and more over it is difficult to diagnose clinically ${ }^{4}$. There have been reports of spigelian hernias mimicking abdominal masses like appendicular mass ${ }^{6}$. A timely $\mathrm{CT}$ scan can prove diagnosis beyond doubt ${ }^{7}$.

CT scan was helpful in this particular case as well as it helped in identifying the entire area of weakness as well as another gap which was not seen on ultrasound.

The spigelian hernia has been repaired by both conventional and laparoscopic approach in today's date, with laparoscopy now having been used in both elective as well as emergency settings ${ }^{8}$. Laparoscopy is advantageous as it is both diagnostic as well as therapeutic.

Open treatment of spigelian hernias involves a planned incision, an oblique incision in skin crease was planned in our case. The hernia sac comes into view only after incising the external oblique as it is an interparietal type of hernia that passes through transversus abdominis and internal oblique and spreads out beneath the aponeurosis of the external oblique. Hernial sac is surrounded by extraperitoneal fatty tissue.

Following identification of sac, management is like other abdominal wall hernias comprising anatomical repair and mesh placement depending on the size of defect or weakness.

In our case, as there was a weakness of $6 \mathrm{~cm}$ with two openings in relation to this weakness, after plicating the openings an onlay mesh was placed.

Laparoscopic repair comprises confirmation of diagnosis and placement of intraperitoneal or extraperitoneal mesh using transabdominal preperitoneal repair (TAPP) or totally extraperitoneal repair (TEP) ${ }^{4}$.

Spigelian hernias are rare, interparietal type of hernias which have high risk undergoing strangulation. Knowledge of symptoms and signs is vital to diagnosis and treatment of these rare type of hernias. We hope that the information in this case note will be helpful in understanding spigelian hernias further.

\section{References}

1. Larson DW, Farley DR. Spigelian hernias: repair and outcome for 81 patients. World $\mathrm{J}$ Surg. 2002;26(10):1277-81.

2. Vos DI, Scheltinga MR. Incidence and outcome of surgical repair of spigelian hernia. The $\mathrm{Br} \mathrm{J}$ Surg. 2004;91(5): 640-4.

3. Thomasset SC, Villatoro E, Wood S, Martin A, Finlay K, Patterson JE. An unsual Spigelian hernia involving the appendix: a case report. Cases J. 2010;3:22.

4. Mittal T, Kumar V, Khullar R, Sharma A, Soni $\mathrm{V}$, Baijal M, et al. Diagnosis and management of Spigelian hernia: A review of literature and our experience. J Minim Access Surg. 2008;4(4):958.

5. Fascetti-Leon F, Gobbi D, Gamba P, Cecchetto G. Neonatal bilateral Spigelian hernia associated with Undescended testes and scalp aplasia cutis. Eur J Paediatr Surg. 2010; 20(2): 123-5.

6. Sinha S, Pushparajasekaran A, Borgstein $\mathrm{R}$, Stoker DL. Spigelian hernia mimicking appedicular mass. Intern Emerg Med. 2010;5(1):77-8.

7. Gough VM, Vella M. Timely computed tomography scan diagnoses spigelian hernia: a case study. Ann R Coll Surg Engl. 2009;91(8):910.

8. Leff DR, Hassell J, Sufi P, Heath D. Emergency and elective laparoscopic repair of Spigelian hernias: two case reports and a review of literature. Surg Laparosc Endosc Percuta Tech. 2009; 19(4):152-5. 